\title{
MODEL FOR RAPID ASSESSMENT OF VULNERABILITY OF OFFICE BUILDINGS TO BLAST USING SWARA AND SMART METHODS (A CASE STUDY OF SWISS RE TOWER)
}

\author{
Jalal NAKHAEI ${ }^{\mathrm{a}}$, Mahdi BITARAFAN ${ }^{\mathrm{b}}$, Shahin LALE AREFI ${ }^{\mathrm{c}}$, Oleg KAPLIŃSKI ${ }^{\mathrm{d}}$ \\ ${ }^{a}$ Dept of Architecture Engineering, Islamic Azad University, Central Tehran Branch, Iran \\ ${ }^{b}$ Dept of Civil Engineering, Engineering Research Institution of Natural Disaster Shakhes Pajouh, \\ P.O. Box 81655-1537, Isfahan, Iran \\ ${ }^{c}$ Dept of Civil Engineering, University of Mohaghegh Ardabili, P.O. Box 56199-11397, Ardabil, Iran \\ ${ }^{d}$ Faculty of Architecture, Poznan University of Technology, Nieszawska Street 13, 60-965 Poznań, Poland
}

Received 17 Feb 2016; accepted 02 May 2016

\begin{abstract}
Accidental and intentional explosions are incidents often destroying buildings and leaving casualties. As a result of these blasts all over the world, demand of safe constructions with less vulnerability to explosions is rising. A large number of office buildings are built each year in many countries, housing large numbers of staff and clients, and due to specific nature and function, activities and services, these buildings are usually centrally located. Their architectural form being vital, therefore the article attempts, firstly, to present indices depicting the building form from the viewpoint of vulnerability to explosion. Secondly, the article presents such indexes as: capability to reduce blast effects, economic factors, simplicity of implementation, relationship among spaces in the crisis condition, and creating the least unusable space. The model of rapid assessment of vulnerability of office buildings forms to blast, SMART (simple multi attribute ranking technique) procedure is used and, applying the SWARA method, the weight of each major index and sub-index is arrived at. The model presented in the paper shows the assessment systems using figures between zero and a hundred, and four levels of vulnerability: weak, medium, good and excellent. The closer the figure to a hundred, the lower the vulnerability of the office building forms to blast. Swiss Re Tower case study was presented in the article rating of vulnerability of this building against explosion. It was found to be equal to $62.11 \%$, and its standing was at medium level.
\end{abstract}

Keywords: vulnerability model, building form, blast loads, MCDM methods.

\section{Introduction}

Every year, remarkable amount of construction work is done around the world in the area of office buildings exposed to damage caused by various threats. Free-Air Blast is one of the most important threats that may damage any office building. The significant point is that the presence of many people, be it staff or clients in these buildings, in addition to activities and services present in this sort of buildings causes that large numbers of them are situated in central parts in a country. Hence, defining the ways to reduce vulnerability of office buildings against blast seems essential so that they may be less vulnerable in the crisis following a Free-Air Blast (Coolset 2010; Graham 2006; Łodygowski, Garstecki 2012; Bitarafan et al. 2012; Jasiński 2010).

On the one hand, the role of architectural form in a building is undeniable. There have been many discussions in this regard by architects in the past and within modern architecture movement, and nowadays this discussion has found more profound context. Because the form is an architect's final statement in creating space, it starts from the initial point of exploration within the architectural space, too. Moreover, form and façade are the first characteristics of a building that are affected by blast and transmit them into structures. Form is significantly affected by the magnitude of blast, and load is transmitted onto structural elements. Therefore, in the need of a model to evaluate the vulnerability of office buildings form is clear and necessary, and is the main aim of the study. In the article, firstly, indexes of building forms affecting vulnerability of office buildings for blast were determined in view of architecture styles, studying bibliography and, in the next stage, their influence and importance was determined with regard to indexes, including resistance to explosion, economic factors, simplicity of implementation, relationship among various spaces in the crisis condition and creating the least unusable space. Finally, a rapid assessment of vulnerability model was created, taking into account architectural form of office buildings exposed to blast.

This article has been corrected since first published. Please see the statement of correct

(http://dx.doi.org/10.3846/13923730.2016.1203479). 
Though appropriate studies and research has been conducted on the subject of designing buildings with regard to vulnerability to explosion, conclusions so far are concerned with entire buildings in general. These studies have not paid attention to remarkable role of the architectural form in making office buildings resistant to explosion. Bitarafan's (2012) research on assessment architecture styles and codifying architectural criteria compatible with civil defence principles is one example. The results of this study point at the fact that among 12 pivots designated for a building, compatible with the principles and goals of civil defence, four included building form features, characteristics of materials used in construction, characteristics of building location on the ground, and the characteristic of the opening, the importance of which was assessed to be more than $63 \%$. Moreover, Bitarafan et al. (2013) dealt with the role of architectural space in resistance of buildings to explosion. This study addressed the issue of absence of codified and detailed criteria to evaluate architectural space and its design. All proposed indexes for architectural space have been generated using ideas provided by experts in the fields of architecture and explosives. Questionnaires were presented to 25 experts to weigh indices using the analytic hierarchy process method. The human-oriented (ergonomic) characteristics of a building space has been found to be the most important factor in facilitating crisis management, followed by location of critical space. Table 1 shows the characteristics arrived at by these experts.

Asgharian Jedi (2007) studied architectural demands in sustainable civil defence, and some conclusions of his work deal with assessment of threats and principles of civil defence, the way of its organization, the importance of civil defence, and efforts to determine conservation value of buildings jeopardized by blast. The Federal Emergency Management Agency conducted a research concerning the risk management, and issuing a series of publications suggesting principles of city planning and principles of construction in view of terrorist attacks. Assessment procedures of threats, risk analysis, determination of the cause of threat, and security design based on the cause threat have been stated in this series (FEMA 2003, 2007).

Gebbeken and Döge (2010) examined the geometry of buildings and the effects of the environment to prevent blast waves from reaching the building. Essentially, the peak pressures and maximum impulses were found to depend on the distance from the blast centre, angle of reflected blast wave, and resistance to the waves. They also found that the structural elements of a building can also reduce the explosive charges. Barakat and Hetherington (1998) studied the blast effects on various building forms, such as cubic, cylindrical, hemisphere, and prismatic forms, and concluded that, in addition to the structural components of the buildings, architectural forms can be effective in reducing the effects of explosion on buildings.

\section{Research method}

The research procedure applied in the paper is a descriptive survey (Delphi), and is based on determining indicators to assess architecture form, and on references. A questionnaire comprising of three sections was designed. First part dealt with percentage of identifying the priorities of indexes of rapid assessment of vulnerability of architecture form of buildings against the blast. These indexes were selected according to the literature of the field, and documents in hand describing the ability to reduce blast effect $\left(C_{1}\right)$, relationship among spaces in the time of crisis $\left(C_{2}\right)$, simplicity of implementation $\left(C_{3}\right)$, economic factors $\left(C_{4}\right)$, and creating the least unusable space $\left(C_{5}\right)$. These major indexes were prioritized by ordinal numbers on the basis of importance rating, so that number one indicates the highest priority. In second part of the questionnaire, sub-indexes of major indexes were defined, and were similarly prioritized based on the importance rating. These sub-indexes include the overall form of the building $\left(C_{1-1}\right)$, combination of building forms $\left(C_{1-2}\right)$, articulation of the corner of the forms $\left(C_{1-}\right.$ $\left.{ }_{3}\right)$, types of roofs $\left(C_{1-4}\right)$, conformity of the architecture form with the structural form $\left(C_{1-5}\right)$, conformity value of the architecture form with the environment $\left(C_{1-6}\right)$, coherence or connection between architectural elements with each other $\left(C_{1-7}\right)$, the surface shape of the exterior shell $\left(C_{1-8}\right)$, ratio of the width to the height of the building $\left(C_{1-9}\right)$, irregularity in the building plan $\left(C_{1-10}\right)$, irregularity in the façade $\left(C_{1-11}\right)$ and the relationship between the building form and the ground $\left(C_{1-12}\right)$. Finally, in the third section, experts graded the alternatives in each of these indexes and sub-indexes. The third part was based on qualitative comparisons, so number 9 was the highest, and number 1 was as the lowest score.

Table 1. Expert community profiles

\begin{tabular}{c|c|c}
\hline Expertise & Education level & Number \\
\hline Civil engineering & Ph.D. & 5 \\
\hline Architecture & Ph.D. & 8 \\
\hline Urban planning & M.Sc. & 5 \\
\hline Civil defence & M.Sc. & 10 \\
\hline \multicolumn{2}{c}{ Total number } & 28 \\
\hline
\end{tabular}

In order to implement the model of rapid assessment of vulnerability of a building form of office buildings to blast, SMART (Simple Multi Attribute Ranking Technique) approach was used. This approach features a combination of qualitative and quantitative indicators to rank the alternatives in hand. To calculate the weights and prioritize the indexes for each alternative, firstly, the range of each index is defined, and indexes defining each alternative are ranked separately. Secondly, the weight and importance of each index is measured. The final weight and prioritization of alternatives come from integration of the weights (Asgharpour 1998). Some previous studies applying SMART approach are: Ahmadi and Ebadi (2014), Chou and Chang (2008), Van den Honert (2001), Lootsma (1996). 
First, indexes and sub-indexes have to be prioritized and weighted in order of their importance using SWARA approach. If $i$ is the number of the major index and $j$ is the number of the sub-index in the SWARA procedure, the weight $W_{i}$ is considered for each index and the weight $W_{i j}$ for each sub-index. A score generated by experts for each alternative is called $U_{i j}$, the rating of $i^{\text {th }}$ index is determined by Eqn (1) using the weighted average of scores of alternatives by sub-indexes related to that index. This value is a number between 1 and 9 (Asgharpourm 1998):

$$
U_{i}=\frac{\sum_{j} w_{i} u_{i j}}{\sum_{j} w_{i j}=1} .
$$

The overall rating $(U)$ is defined in terms of a score given to each index, and their weight, according to Eqn (2):

$$
U=\frac{\sum_{i} U_{i} W_{i}}{\sum_{i} w_{i}=1} .
$$

The value of $U$ is a number between 1 and 9 that reveals the desirability rate of the architecture form of an office building in a situation of blast. The desirability level of the architecture form of the office building will arise from this model. Provided that this level is shown by parameter $L$, the Eqn (3) is used to calculate the respective percentage:

$$
L=\frac{U}{9} \times 100 .
$$

The level of $L$ is reflected in the model evaluation (see Table 2).

Table 2. Various levels of the assessment model of the architecture form of office buildings in case of blast

\begin{tabular}{c|c}
\hline Rating & Level \\
\hline Weak & $L<40$ \\
\hline Medium & $40 \leq L<70$ \\
\hline Good & $70 \leq L<90$ \\
\hline Excellent & $L \geq 90$ \\
\hline
\end{tabular}

\subsection{SWARA approach}

Multiple Criteria Decision Making (MCDM) substantially evolved during the past decades and became one of the most important areas in Operational Research/Management Science (Kaplinski et al. 2014; Zavadskas et al. 2015a, 2015b). Weight assessment is an important issue in many Multi Attribute Decision Making (MADM) problems (Kaplinski, Tamošaitienè 2015). Some weight assessment methods described in articles are comprised of the following: analytic hierarchy process (AHP) (Saaty 1980), analytic network process (ANP) (Saaty, Vargas 2007), Entropy (Shannon 1948; Lazauskaite et al. 2015), FARE (Ginevicius 2011), SWARA (Kersuliene et al. 2010; Stanujkic et al. 2015) and so on; among these methods, SWARA is one of the most recent procedures.

In this method, an expert plays a significant role in assessment and calculation of weights. Moreover, each expert selects the importance of each index. Then, he ranks all indexes from the first to the last, and uses his knowledge and expertise. Based on this method, the most significant index ranks 1 and the least significant ranks last. Overall ranks are determined by the experts' team on the basis of the average value of scores.

The experts' ability to estimate the relative importance of indexes in the process of weight determination is the most important element of this procedure. Furthermore, this procedure is relevant for coordinating and collecting data from experts. SWARA is an uncomplicated method, and an expert can easily apply it as well. The main advantage of applying this procedure to decision-making is that in some problems, priorities are defined in terms of company or country policies, and there is no need to evaluate index rankings.

All developments in decision-making models on the basis of SWARA have been mentioned in the following publications: Stanujkic et al. (2015), Bitarafan et al. (2014), Ruzgys et al. (2014), Vafaeipour et al. (2014), Dehnavi et al. (2015), Keršulienè and Turskis (2014), Hashemkhani Zolfani and Bahrami (2014).

The procedure of determining weights of the index is presented in Figure 1.

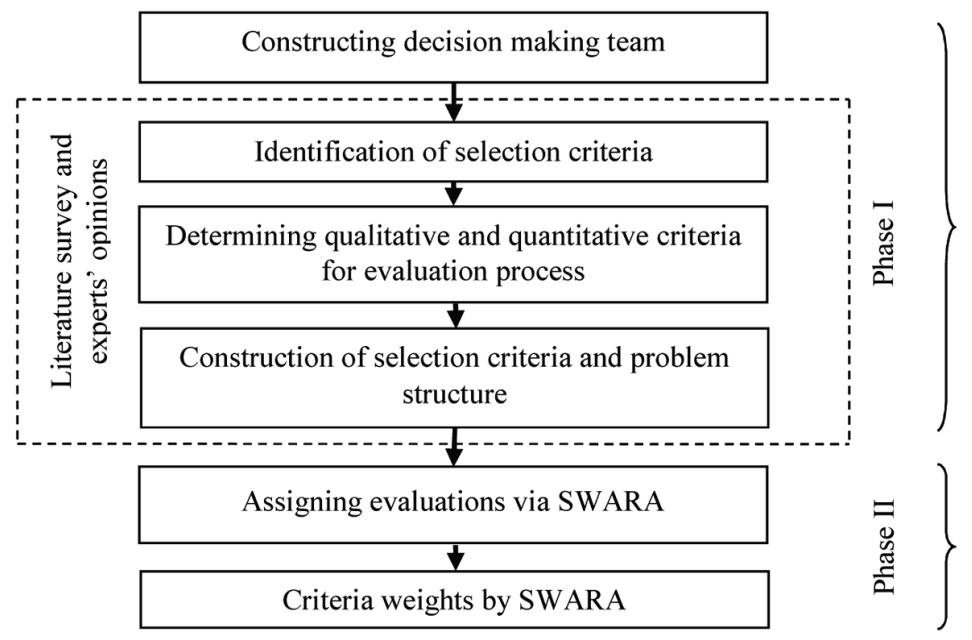

Fig. 1. Schematic display of weighting process of criteria using SWARA method 


\section{Discussion and results}

In this part, firstly, the results of application of SWARA method prioritizing major indexes of architecture form, and sub-indexes are mentioned; then, using the SMART approach, a model for rapid assessment of vulnerability of office buildings architecture form of to blast is presented.

\subsection{The results of SWARA for prioritizing indexes and sub-indexes}

The experts were asked to prioritize indexes in each section. The results of ranking have been summarized based on the average of their views.

\subsubsection{Major indexes}

On the basis of experts' ideas concerning the architectural form, the index of capability to reduce blast effects is identified as the first priority. The second priority is the index of the relationship among spaces in the crisis condition. Economic and simplicity of implementation indexes are third and fourth priorities, as presented in Table 3.

Table 3. Architectural priorities reflected by indexes

\begin{tabular}{l|c|c|c}
\hline \multicolumn{1}{c|}{ Indexes } & $\begin{array}{c}\text { Index } \\
\text { symbol }\end{array}$ & $\begin{array}{c}\text { Averages of } \\
\text { priority (experts) }\end{array}$ & Priorities \\
\hline $\begin{array}{l}\text { Capability to reduce } \\
\text { blast effect }\end{array}$ & $C_{1}$ & 1.10 & 1 \\
\hline $\begin{array}{l}\text { Relationship among } \\
\text { spaces in the crisis } \\
\text { condition }\end{array}$ & $C_{2}$ & 1.84 & 2 \\
\hline $\begin{array}{l}\text { Simplicity of } \\
\text { implementation }\end{array}$ & $C_{3}$ & 4.90 & 5 \\
\hline $\begin{array}{l}\text { Economic factors } \\
C_{4}\end{array}$ & 3.12 & 3 \\
\hline $\begin{array}{l}\text { Creating the least } \\
\text { unusable space }\end{array}$ & $C_{5}$ & 3.96 & 4 \\
\hline
\end{tabular}

The first column in the left of Table 4 shows indexes which have been arranged according to the priorities defined by experts. As described before, priorities of indexes are determined in this manner. The second column from the left, $S_{j}$, is the comparison of the value importance of indexes. Assessment of indexes was conducted by experts using a questionnaire. Experts associated with this research responded to the questionnaire. Note that an index placed within the highest rating of importance is compared only with the lower index than itself. The assessment procedure in this method uses the fact that each evaluated index is compared only to a higher (better) index. Eventually, all indexes are compared with each other. The assessment is in percentage terms. The assessment scale is based on 5 percent steps. i.e., experts indicate comparative and value differences on the basis of 5 percent increments: $5 \%, 10 \%, 15 \%, 20 \%$ and so on. Final numbers in this part are calculated from the arithmetic average of experts' ideas, as shown in the table.

The third column $K_{j}$ shows the way of assessing and calculating the final weight. Each $S_{j}$ is added to number 1 to facilitate, in the next step, the primary assessment. The reason why number 1 is added is that $S_{j}$ in the first index is zero, and if it was not done, the calculation would be impossible.

In the fourth column, $W_{j}$ is obtained dividing the first index $K_{j}$ of by second index $S_{j}$. Proceeding in this order, the value of indexes rises by comparison with the index higher than the compared one and, finally, each index is weighed against all indexes and, in fact, it integrates the primary assessment.

In the fifth column $Q_{j}$ is gained dividing each $W_{j}$ by the sum from column $W_{j}$. In effect, the value of each index determines the final index weight within from the total value of all indexes.

Based on SWARA method presented in Table 4, the capability index of blast effect reduction has the weight of $39.03 \%$. The index of relationship among spaces in the crisis condition takes the second place with the weight of $21.68 \%$. Then comes the economic index, and the index reflecting the least unusable space and simplicity of implementation, with their respective weights of $16.26 \%$ and $13.01 \%$ and $10.01 \%$.

\subsubsection{Sub-indexes}

Weights of indexes have been obtained using SWARA data analysis. The column "Weight" in Tables 5 to 9 displays the weight of each sub-index, reflecting the capability of reducing blast effect, relationship among spaces in the crisis condition, simplicity of implementation, economic factors, and capability of creating the least unusable space. Please note that the final weights of sub-index-

Table 4. Priorities and final weight of indexes of the architecture form

\begin{tabular}{c|c|c|c|c}
\hline Index & $\begin{array}{c}\text { Comparative } \\
\text { importance of } \\
\text { average value } s_{j}\end{array}$ & $\begin{array}{c}\text { Coefficient } \\
k_{j}=s_{j}+1\end{array}$ & $\begin{array}{c}\text { Recalculated weight } \\
w_{j}=\frac{x_{j-1}}{k_{j}}\end{array}$ & $\begin{array}{c}\text { Weight } \\
q_{j}=\frac{w_{j}}{\sum w_{j}}\end{array}$ \\
\hline$C_{1}$ & & 1 & 1.0000 & 0.3903 \\
\hline$C_{2}$ & 0.8 & 1.8 & 0.5556 & 0.2168 \\
\hline$C_{4}$ & 0.333 & 1.333 & 0.4167 & 0.1626 \\
\hline$C_{5}$ & 0.250 & 1.250 & 0.3333 & 0.1301 \\
\hline$C_{3}$ & 0.300 & 1.300 & 0.2564 & 0.1001 \\
\hline
\end{tabular}


Table 5. Priorities and final weights of sub-indexes reflecting the capability of reducing blast effect

\begin{tabular}{c|c|c|c|c}
\hline Index & $\begin{array}{c}\text { Comparative } \\
\text { importance of } \\
\text { average value } s_{j}\end{array}$ & $\begin{array}{c}\text { Coefficient } \\
k_{j}=s_{j}+1\end{array}$ & $\begin{array}{c}\text { Recalculated weight } \\
w_{j}=\frac{x_{j-1}}{k_{j}}\end{array}$ & $\begin{array}{c}\text { Weight } \\
q_{j}=\frac{w_{j}}{\sum w_{j}}\end{array}$ \\
\hline$C_{1-12}$ & 0.200 & 1.200 & 1.0000 & 0.1262 \\
\hline$C_{1-1}$ & 0.200 & 1.200 & 0.8333 & 0.1052 \\
\hline$C_{1-2}$ & 0.010 & 1.010 & 0.6944 & 0.0876 \\
\hline$C_{1-8}$ & 0.020 & 1.020 & 0.6876 & 0.0868 \\
\hline$C_{1-10}$ & 0.050 & 1.050 & 0.6741 & 0.0851 \\
\hline$C_{1-9}$ & 0.050 & 1.050 & 0.6420 & 0.0810 \\
\hline$C_{1-11}$ & 0.030 & 1.030 & 0.6114 & 0.0772 \\
\hline$C_{1-5}$ & 0.010 & 1.010 & 0.5936 & 0.0742 \\
\hline$C_{1-4}$ & 0.050 & 1.050 & 0.5877 & 0.0706 \\
\hline$C_{1-7}$ & 0.050 & 1.050 & 0.5597 & 0.0673 \\
\hline$C_{1-6}$ & 0.050 & 1.050 & 0.5331 & 0.0641 \\
\hline$C_{1-3}$ & & 0.5077 & \\
\hline
\end{tabular}

es arise from the product of initial weight of sub-indexes and the weight of major index. For example, the weight of sub-indexes reflecting the capability of reducing blast effect is acquired from multiplying sub-indexes of this index by the weight reflecting the capability of reducing blast effect. This process is the same for other indexes. Priorities and final weights of sub-indexes reflecting the capability of reducing blast effect $\left(C_{1}\right)$ stem from SWARA, and are shown in Table 5. According to the method, secondary index $C_{1-12}$ with the weight of 0.1262 is first. Secondary indexes $C_{1-1}$ and $C_{1-2}$ with the weights of 0.1052 and 0.0876 are second and third, respectively. In addition, sub-index $C_{1-3}$ with the weight of 0.0641 is the least important one within the major index reflecting the capability of reducing blast effect $\left(C_{1}\right)$.
Table 6 indicates priorities and final weights of sub-indexes reflecting relationship among spaces in the crisis condition $\left(C_{2}\right)$. Based on the results of this procedure, secondary index $C_{2-12}$ with the weight of 0.1744 is ranked as first. Then, secondary indexes $C_{2-1}$ and $C_{2-2}$ with weights of 0.1727 and 0.1439 are second and third, respectively. Sub-index $C_{2-3}$ with the weight of 0.0229 is the least important one within the major index reflecting relationship among spaces in the crisis condition $\left(C_{2}\right)$.

Priorities and final weights of sub-indexes of simplicity of implementation according to SWARA are presented in Table 7. In accordance with this method, secondary index $C_{3-1}$ with the weight of 0.1658 is first. Secondary indexes $C_{3-10}$ and $C_{3-11}$ with weights of 0.1382 and 0.1368 are second and third, respectively. The subindex $C_{3-3}$ with the weight of 0.0215 is the least impor-

Table 6. Priorities and final weights of sub-indexes reflecting relationship among spaces in crisis condition

\begin{tabular}{c|c|c|c|c}
\hline Index & $\begin{array}{c}\text { Comparative } \\
\text { importance of } \\
\text { average value } s_{j}\end{array}$ & $\begin{array}{c}\text { Coefficient } \\
k_{j}=s_{j}+1\end{array}$ & $\begin{array}{c}\text { Recalculated weight } \\
w_{j}=\frac{x_{j-1}}{k_{j}}\end{array}$ & $\begin{array}{c}\text { Weight } \\
q_{j}\end{array}$ \\
\hline$C_{2-12}$ & 1 & 1.0000 & 0.1744 \\
\hline$C_{2-1}$ & 0.010 & 1.010 & 0.9901 & 0.1727 \\
\hline$C_{2-2}$ & 0.200 & 1.200 & 0.8251 & 0.1439 \\
\hline$C_{2-8}$ & 0.300 & 1.300 & 0.6347 & 0.1107 \\
\hline$C_{2-10}$ & 0.250 & 1.250 & 0.5077 & 0.0885 \\
\hline$C_{2-9}$ & 0.030 & 1.030 & 0.4930 & 0.0860 \\
\hline$C_{2-11}$ & 0.350 & 1.350 & 0.3652 & 0.0637 \\
\hline$C_{2-5}$ & 0.400 & 1.400 & 0.2608 & 0.0455 \\
\hline$C_{2-4}$ & 0.250 & 1.250 & 0.2087 & 0.0364 \\
\hline$C_{2-7}$ & 0.300 & 1.300 & 0.1605 & 0.0280 \\
\hline$C_{2-6}$ & 0.020 & 1.020 & 0.1574 & 0.0274 \\
\hline$C_{2-3}$ & 0.200 & 1.200 & 0.1311 & 0.0229 \\
\hline
\end{tabular}


Table 7. Priorities and final weights of sub-indexes of the simplicity of implementation

\begin{tabular}{c|c|c|c|c}
\hline Index & $\begin{array}{c}\text { Comparative } \\
\text { importance of } \\
\text { average value } s_{j}\end{array}$ & $\begin{array}{c}\text { Coefficient } \\
k_{j}=s_{j}+1\end{array}$ & $\begin{array}{c}\text { Recalculated weight } \\
w_{j}=\frac{x_{j-1}}{k_{j}}\end{array}$ & $\begin{array}{c}\text { Weight } \\
q_{j}=\frac{w_{j}}{\sum w_{j}}\end{array}$ \\
\hline$C_{3-1}$ & & 1 & 1.0000 & 0.1658 \\
\hline$C_{3-10}$ & 0.200 & 1.200 & 0.8333 & 0.1382 \\
\hline$C_{3-11}$ & 0.010 & 1.010 & 0.8251 & 0.1368 \\
\hline$C_{3-5}$ & 0.300 & 1.300 & 0.6347 & 0.1052 \\
\hline$C_{3-9}$ & 0.020 & 1.020 & 0.6222 & 0.1032 \\
\hline$C_{3-2}$ & 0.300 & 1.300 & 0.4786 & 0.0794 \\
\hline$C_{3-8}$ & 0.010 & 1.010 & 0.4739 & 0.0786 \\
\hline$C_{3-7}$ & 0.250 & 1.250 & 0.3791 & 0.0466 \\
\hline$C_{3-12}$ & 0.350 & 1.350 & 0.2808 & 0.0350 \\
\hline$C_{3-4}$ & 0.330 & 1.330 & 0.2112 & 0.0269 \\
\hline$C_{3-6}$ & 0.300 & 1.300 & 0.1624 & 0.0215 \\
\hline$C_{3-3}$ & 0.250 & 1.250 & 0.1299 & 0.0629 \\
\hline
\end{tabular}

tant one within the major index reflecting simplicity of implementation $\left(C_{3}\right)$.

Table 8 indicates priorities and final weights of subindexes reflecting economic factors $\left(C_{4}\right)$. In accordance with this method, secondary index $C_{4-1}$ with the weight of 0.1950 is ranked first. Then, secondary indexes $C_{4-10}$ and $C_{4-11}$ with weights of 0.1500 and 0.1250 are second and third, respectively. Sub-index $C_{4-3}$ with the weight of 0.0329 the least important one within the major index reflecting economic factors $\left(C_{4}\right)$.

Priorities and final weights of sub-indexes reflecting the least unusable space are displayed in Table 9. In accordance with the SWARA method, secondary index $C_{5-1}$ with the weight of 0.1877 is first. Secondary indexes $C_{5-10}$ and $C_{5-5}$ with the weights of 0.1564 and 0.1203 are second and third, respectively. In addition, the sub-index $C_{5-9}$ with the weight of 0.0270 is as the least important within major indexes reflecting the least unusable space $\left(C_{5}\right)$.

\subsection{Scores given to alternatives in each index and sub-index}

\subsubsection{Sub-index reflecting the overall form of the building}

Table 10 presents averages of experts' scores for a variety forms buildings within major indexes. Five alternative forms were considered: the cube $\left(A_{1}\right)$, cylinder $\left(A_{2}\right)$, pyramid $\left(A_{3}\right)$, cone $\left(A_{4}\right)$ hemisphere $\left(A_{5}\right)$. According to experts' opinions, the cone has the highest rating of 8.89., and this index reflects the capability of reducing blast effect. The hemisphere, pyramid, cube and cylinder come next, with scores of 7.44, 7.22, 3.14 and 1.32 , respectively. The index of relationship among spaces in the crisis

Table 8. Priorities and final weights of sub-indexes reflecting economic factors

\begin{tabular}{c|c|c|c|c}
\hline Index & $\begin{array}{c}\text { Comparative } \\
\text { importance of } \\
\text { average value } s_{j}\end{array}$ & $\begin{array}{c}\text { Coefficient } \\
k_{j}=s_{j}+1\end{array}$ & $\begin{array}{c}\text { Recalculated weight } \\
w_{j}=\frac{x_{j-1}}{k_{j}}\end{array}$ & $\begin{array}{c}\text { Weight } \\
w_{j}\end{array}$ \\
\hline$C_{4-1}$ & & 1 & 1.0000 & 0.1950 \\
\hline$C_{4-10}$ & 0.300 & 1.300 & 0.7692 & 0.1500 \\
\hline$C_{4-11}$ & 0.200 & 1.200 & 0.6410 & 0.1250 \\
\hline$C_{4-5}$ & 0.250 & 1.250 & 0.5128 & 0.1000 \\
\hline$C_{4-9}$ & 0.350 & 1.350 & 0.3799 & 0.0741 \\
\hline$C_{4-2}$ & 0.150 & 1.150 & 0.3303 & 0.0644 \\
\hline$C_{4-8}$ & 0.020 & 1.020 & 0.3238 & 0.0632 \\
\hline$C_{4-7}$ & 0.100 & 1.100 & 0.2944 & 0.0574 \\
\hline$C_{4-12}$ & 0.010 & 1.010 & 0.2915 & 0.0568 \\
\hline$C_{4-4}$ & 0.200 & 1.200 & 0.2429 & 0.0474 \\
\hline$C_{4-6}$ & 0.400 & 1.400 & 0.1735 & 0.0338 \\
\hline$C_{4-3}$ & 0.030 & 1.030 & 0.1685 & 0.0329 \\
\hline
\end{tabular}


Table 9. Priorities and final weights of sub-indexes reflecting the least unusable space

\begin{tabular}{c|c|c|c|c}
\hline Index & $\begin{array}{c}\text { Comparative } \\
\text { importance of } \\
\text { average value } s_{j}\end{array}$ & $\begin{array}{c}\text { Coefficient } \\
k_{j}=s_{j}+1\end{array}$ & $\begin{array}{c}\text { Recalculated weight } \\
w_{j}=\frac{x_{j-1}}{k_{j}}\end{array}$ & $\begin{array}{c}\text { Weight } \\
q_{j}=\frac{w_{j}}{\sum w_{j}}\end{array}$ \\
\hline$C_{5-1}$ & & 1 & 1.0000 & 0.1877 \\
\hline$C_{5-10}$ & 0.200 & 1.200 & 0.8333 & 0.1564 \\
\hline$C_{5-5}$ & 0.300 & 1.300 & 0.6410 & 0.1203 \\
\hline$C_{5-8}$ & 0.020 & 1.020 & 0.6285 & 0.1180 \\
\hline$C_{5-7}$ & 0.300 & 1.300 & 0.4834 & 0.0908 \\
\hline$C_{5-11}$ & 0.200 & 1.200 & 0.4029 & 0.0756 \\
\hline$C_{5-2}$ & 0.100 & 1.100 & 0.3662 & 0.0688 \\
\hline$C_{5-3}$ & 0.350 & 1.350 & 0.2713 & 0.0509 \\
\hline$C_{5-4}$ & 0.400 & 1.400 & 0.1938 & 0.0364 \\
\hline$C_{5-12}$ & 0.020 & 1.020 & 0.1900 & 0.0357 \\
\hline$C_{5-6}$ & 0.100 & 1.100 & 0.1727 & 0.0324 \\
\hline$C_{5-9}$ & 0.200 & 1.200 & 0.1439 & 0.0270 \\
\hline
\end{tabular}

condition gives the cube a score of 7.11, and other forms $6.89,5.96$ and 2.11, respectively. The cube from the viewpoint of simplicity of implementation is the simplest alternative for implementation, with the rating of 8.89 and the alternative of the cone is the most complex choice for implementation, with the score of 1.05 . The cube in the light of economic factors has the lowest score 8.88 reflecting its relatively low cost of construction, and the conical form is the most costly. The alternative of a cube within the index of the least unusable space has the highest rating of 8.96 and then come the cylinder, pyramid, hemisphere and cone with scores of 5.22, 4.12, 3.13 and 1.88 , respectively.

Table 10. Averages of experts' scores for alternatives of overall forms of buildings as major index

\begin{tabular}{|c|c|c|c|c|c|c|}
\hline \multirow{2}{*}{\multicolumn{2}{|c|}{$\begin{array}{l}\text { General Form of } \\
\text { Building }\end{array}$}} & \multicolumn{5}{|c|}{ Alternatives } \\
\hline & & \multirow{2}{*}{$\begin{array}{c}\mathrm{A}_{1} \\
3.14 \\
\end{array}$} & \multirow{2}{*}{$\begin{array}{c}\mathrm{A}_{2} \\
1.32 \\
\end{array}$} & \multirow{2}{*}{$\begin{array}{c}\mathrm{A}_{3} \\
7.22 \\
\end{array}$} & \multirow{2}{*}{$\begin{array}{c}\mathrm{A}_{4} \\
8.89 \\
\end{array}$} & \multirow{2}{*}{$\begin{array}{c}\mathrm{A}_{5} \\
7.44 \\
\end{array}$} \\
\hline \multirow{5}{*}{ index } & $\mathrm{C}_{1}$ & & & & & \\
\hline & $\mathrm{C}_{2}$ & 2.11 & 5.96 & 7.11 & 8.99 & 6.89 \\
\hline & $\mathrm{C}_{3}$ & 8.89 & 5.27 & 2.29 & 1.05 & 4.09 \\
\hline & $\mathrm{C}_{4}$ & 8.88 & 5.19 & 2.17 & 1.11 & 4.64 \\
\hline & $\mathrm{C}_{5}$ & 8.96 & 5.22 & 4.12 & 1.88 & 3.13 \\
\hline
\end{tabular}

\subsubsection{Combination of building forms}

Six combinations of linear $\left(B_{1}\right)$, radial $\left(B_{2}\right)$, centripetal $\left(B_{3}\right)$, networked $\left(B_{4}\right)$, clustered $\left(B_{5}\right)$ and u-shape $\left(B_{6}\right)$ forms are surveyed in this section. Table 11 presents averages of experts' scores for types of building forms reflected as major indexes. Based on their views, the centripetal form with the rating of 8.89 has the highest score within the index of capability to reduce blast effects. The linear, u-shape, networked, clustered and radial alternatives were given scores of 8.41, 4.10, 3.54, 3.42 and 3.18, respectively. As to the index of relationship among spaces in the crisis condition, the centripetal form has the highest score of 7.95 and the linear form alternative is last with the score of 1.69. The of linear form alternative within the index of simplicity of implementation has the score of 8.87 , and the clustered form is the most difficult to implement, with the score of 1.11. As to the economic index, the alternative of linear form is the least costly with the rating of 8.79 , while the clustered form is the most costly. Within the index of creating the least unusable space, the linear form alternative has the highest score of 8.78 , whereas u-shape, radial, centripetal, clustered and networked forms were given scores at 6.78, 5.9, 4.54, 4.15 and 3.34 , respectively.

Table 11. Averages of experts' scores for alternatives of combination of building forms within the major indexes

\begin{tabular}{l|c|c|c|c|c|c|c}
\hline \multicolumn{2}{c|}{$\begin{array}{c}\text { Combination of } \\
\text { Building Forms }\end{array}$} & \multicolumn{7}{|c}{ Alternatives } \\
\cline { 2 - 8 } & $B_{1}$ & $B_{2}$ & $B_{3}$ & $B_{4}$ & $B_{5}$ & $B_{6}$ \\
\hline \multirow{4}{*}{ index } & $C_{1}$ & 8.41 & 3.18 & 8.89 & 3.54 & 3.42 & 4.1 \\
\cline { 2 - 8 } & $C_{2}$ & 1.69 & 3.22 & 7.95 & 3.96 & 4.11 & 3.12 \\
\cline { 2 - 8 } & $C_{3}$ & 8.87 & 4.1 & 5.07 & 5.1 & 1.11 & 6.5 \\
\cline { 2 - 8 } & $C_{4}$ & 8.79 & 4.13 & 5.1 & 5.13 & 1.14 & 5.69 \\
\cline { 2 - 8 } & $C_{5}$ & 8.78 & 5.9 & 4.54 & 3.34 & 4.15 & 6.78 \\
\hline
\end{tabular}

\subsubsection{Corner articulation of architectural forms}

Table 12 represents the averages of experts' scores for corner articulation of architectural forms within major indexes. Two alternatives with no corner articulation $\left(D_{1}\right)$ and circular corner articulation $\left(D_{2}\right)$ were considered. With respect to two indexes of capability to reduce blast effects and relationship among spaces in the crisis condition, the experts consider alternative $D_{2}$ with the scores of 9.23 and 8.97 to be better than alternative $D_{1}$. On the other hand, as far as indexes of simplicity of implementation, economic and creating the least unusable space are 
Table 12. Averages of experts' scores for alternatives of corner articulation of architectural forms within the major indexes

\begin{tabular}{l|c|c|c}
\hline \multirow{2}{*}{ Corner articulation of forms } & \multicolumn{2}{c}{ Alternatives } \\
\cline { 3 - 4 } & $C_{1}$ & $D_{1}$ & $D_{2}$ \\
\hline \multirow{4}{*}{ index } & $C_{2}$ & 3.14 & 9.23 \\
\cline { 2 - 4 } & $C_{3}$ & 8.97 & 8.97 \\
\cline { 2 - 4 } & $C_{4}$ & 8.91 & 3.22 \\
\cline { 2 - 4 } & $C_{5}$ & 7.89 & 3.16 \\
\hline
\end{tabular}

Table 13. Averages of experts' scores for roof alternatives within the major indexes

\begin{tabular}{l|c|c|c|c|c|c}
\hline \multirow{2}{*}{ Types of roofs } & \multicolumn{5}{c}{ Alternatives } \\
\cline { 3 - 7 } \multicolumn{1}{c|}{} & $E_{1}$ & $E_{2}$ & $E_{3}$ & $E_{4}$ & $E_{5}$ \\
\hline \multirow{4}{*}{ index } & $C_{1}$ & 6.16 & 8.97 & 2.18 & 5.1 & 3.22 \\
\cline { 2 - 7 } & $C_{2}$ & 1.9 & 8.9 & 3.69 & 2.98 & 1.97 \\
\cline { 2 - 7 } & $C_{3}$ & 1.22 & 8.88 & 6.12 & 5.11 & 3.12 \\
\cline { 2 - 7 } & $C_{4}$ & 1.23 & 8.89 & 5.22 & 5.23 & 3.1 \\
\cline { 2 - 7 } & $C_{5}$ & 7.91 & 2.42 & 8.91 & 8.2 & 7.69 \\
\hline
\end{tabular}

concerned, alternative $D_{1}$ is better than $D_{2}$ with the scores of $8.98,8.91$ and 7.89 .

\subsubsection{Variety of roofs}

Five roofs in: conical $\left(E_{1}\right)$, flat $\left(E_{2}\right)$, gabled $\left(E_{3}\right)$, domed $\left(E_{4}\right)$ and pyramidal $\left(E_{5}\right)$ forms are considered in this section. Table 13 shows the averages of experts' scores. Basing on experts' opinions, regarding the index of capability to reduce blast effects, the flat roof alternative was rated the highest at 8.97. Conical, domed, pyramidal and gabled roves were scored 6.16, 5.10, 3.22 and 2.18, respectively. As to the relationship among spaces in the crisis condition, the flat form alternative has the highest score of 8.9, while gabled, domed, pyramidal and conical roof forms were scored at 3.69, 2.98, 1.97 and 1.90, respectively. The flat roof is the simplest implementation alternative, with the score of 8.88 while the pyramidal roof is the most difficult to build, with the score of 1.22. As to the economic index, the flat roof is the most economical alternative with the rating of 8.89 , and the conical roof with the score of 1.23 is the costliest alternative. As to the index of creating the least unusable space, the gabled has comprises the highest score of 8.91, while the flat roof has the lowest score of 2.42 .

\subsubsection{Conformity of the architecture form with the structural form}

Table 14 shows averages of experts' scores for conformity of the architectural form with the structural form. Only two alternatives of completely conformable $\left(F_{1}\right)$, and lack of conformity $\left(F_{2}\right)$ were evaluated. Based on experts' views, alternative $F_{1}$ was better than $F_{2}$ in all indexes, with scores of $8.79,8.95,8.11,7.77$ and 5.34 , respectively.
Table 14. Averages of experts' scores for alternatives of the conformity of architecture form with the structural form within the major indexes

\begin{tabular}{l|c|c|c}
\hline \multirow{2}{*}{$\begin{array}{c}\text { Conformity of architecture form } \\
\text { with the structural form }\end{array}$} & \multicolumn{2}{|c}{ Alternatives } \\
\cline { 2 - 4 } & $C_{1}$ & $F_{1}$ & $F_{2}$ \\
\hline \multirow{4}{*}{ index } & $C_{2}$ & 8.79 & 2.99 \\
\cline { 2 - 4 } & $C_{3}$ & 8.11 & 3.2 \\
\cline { 2 - 4 } & $C_{4}$ & 7.77 & 1.88 \\
\cline { 2 - 4 } & $C_{5}$ & 5.34 & 3.11 \\
\hline
\end{tabular}

\subsubsection{Conformity of architectural form with the environmental form}

Table 15 reveals averages of experts' opinions about conformity of the architectural form with environmental form. Three alternatives: perfectly conformable $\left(G_{1}\right)$, quite conformable $\left(G_{2}\right)$ and lack of conformity $\left(G_{3}\right)$ were assessed. Among those alternatives, i.e., $C_{1}, C_{2}$ and $C_{5}$, $G_{1}$ is the best, scoring 8.91, while the other alternatives scored 8.89 and 5.12, respectively. On the other hand, $G_{2}$ is best alternative, compared to $C_{3}$ and $C_{4}$ with scores of 6.13 and 6.33 , respectively.

Table 15. Averages of experts' scores for alternatives reflecting conformity of architectural form with environmental form within the major indexes

\begin{tabular}{c|c|c|c|c}
\hline \multirow{2}{*}{$\begin{array}{c}\text { Conformity of architectural } \\
\text { form with environmental form }\end{array}$} & \multicolumn{3}{|c}{ Alternatives } \\
\cline { 2 - 5 } & $G_{1}$ & $G_{2}$ & $G_{3}$ \\
\hline \multirow{4}{*}{ index } & $C_{1}$ & 8.91 & 5.89 & 3.12 \\
\cline { 2 - 5 } & $C_{2}$ & 8.89 & 5.12 & 3.24 \\
\cline { 2 - 5 } & $C_{3}$ & 5.18 & 6.13 & 5.19 \\
\cline { 2 - 5 } & $C_{4}$ & 5.23 & 6.33 & 5.12 \\
\cline { 2 - 5 } & $C_{5}$ & 5.12 & 4.22 & 3.23 \\
\hline
\end{tabular}

\subsubsection{Coherence or connection between architectural elements with each other}

Table 16 presents averages of experts' scores for coherence or connection between architectural elements with each other. Two alternatives of coherence between architecture elements $\left(H_{1}\right)$ and connection between elements

Table 16. Averages of experts' scores assessing coherence or connection between architectural elements with each other within the major index

\begin{tabular}{l|c|c|c}
\hline \multirow{2}{*}{$\begin{array}{c}\text { Coherence or connection between } \\
\text { architectural elements with each other }\end{array}$} & \multicolumn{2}{c}{ Alternatives } \\
\cline { 2 - 4 } & $C_{1}$ & 7.17 & $H_{2}$ \\
\hline \multirow{4}{*}{ index } & $C_{2}$ & 5.17 & 4.14 \\
\cline { 2 - 4 } & $C_{3}$ & 3.12 & 6.17 \\
\cline { 2 - 4 } & $C_{4}$ & 3.33 & 6.12 \\
\cline { 2 - 4 } & $C_{5}$ & 7.34 & 4.28 \\
\hline
\end{tabular}


$\left(H_{2}\right)$ were studied. According to experts, $H_{1}$ is better than $\mathrm{H}_{2}$ in two indexes of $C_{1}$ and $C_{5}$ with scores of 7.17 and 7.34, while alternative $H_{2}$ in indexes of $C_{2}, C_{3}$ and $C_{4}$ with scores of 5.41, 6.17 and 6.12 is better than $H_{1}$.

\subsubsection{The surface shape of the exterior shell}

In this section, five forms of shells: convex $\left(I_{1}\right)$, concave $\left(I_{2}\right)$, flat $\left(I_{3}\right)$, protruding broken $\left(I_{4}\right)$ and broken depressed $\left(I_{5}\right)$ were compared. Table 17 illustrates averages of experts' scores for shape of surface of the exterior shell. According to the experts, alternative $I_{1}$ in the index $C_{1}$ with the rating of 8.23, alternative $I_{2}$ in the index $C_{2}$ with the rating of 8.31, alternative $I_{3}$ in indexes $C_{3}$ and $C_{4}$ with scores of 8.79 and 8.88, and alternative $I_{4}$ in index of $C_{5}$ with the rating of 7.45 are the best alternatives.

Table 17. Averages of experts' scores for alternatives of shape of surface of exterior shell within the major indexes

\begin{tabular}{c|c|c|c|c|c|c}
\hline \multirow{2}{*}{$\begin{array}{c}\text { Surface shape } \\
\text { of exterior shell }\end{array}$} & \multicolumn{5}{|c}{ Alternatives } \\
\cline { 2 - 7 } & $I_{1}$ & $I_{2}$ & $I_{3}$ & $I_{4}$ & $I_{5}$ \\
\hline \multirow{4}{*}{ index } & $C_{1}$ & 8.23 & 3.21 & 6.19 & 7.02 & 4.05 \\
\cline { 2 - 7 } & $C_{2}$ & 4.2 & 8.31 & 5.11 & 3.12 & 7.18 \\
\cline { 2 - 7 } & $C_{3}$ & 2.29 & 2.22 & 8.79 & 5.09 & 5.14 \\
\cline { 2 - 7 } & $C_{4}$ & 2.22 & 2.21 & 8.88 & 5.42 & 5.43 \\
\cline { 2 - 7 } & $C_{5}$ & 7.38 & 2.19 & 6.27 & 7.45 & 2.33 \\
\hline
\end{tabular}

\subsubsection{Ratio of the width to the height of the building}

Table 18 displays averages of experts' scores for the ratio of width to the height of the building. Two $\left(J_{1}\right)$ alternatives and $\left(J_{2}\right)$ were weighed. According to the experts' opinions, alternative $J_{2}$ in two indexes $C_{1}$ and $C_{5}$ with scores of 6.27 and 5.32, respectively, is better than $J_{1}$. On the other hand, as far as $C_{2}, C_{3}$ and $C_{4}$ with scores of $8.98,8.09$ and 7.86 , respectively, are concerned, is defined better than $J_{2}$.

Table 18. Averages of experts' scores for alternatives of the ratio of width to height of the building within the major index

\begin{tabular}{c|c|c|c}
\hline \multirow{2}{*}{ Ratio of width to height of the building } & \multicolumn{2}{|c}{ Alternatives } \\
\cline { 3 - 4 } & $J_{1}$ & $J_{2}$ \\
\hline \multirow{4}{*}{ index } & $C_{1}$ & 3.02 & 6.27 \\
\cline { 2 - 4 } & $C_{2}$ & 8.98 & 2.16 \\
\cline { 2 - 4 } & $C_{3}$ & 8.09 & 2.19 \\
\cline { 2 - 4 } & $C_{4}$ & 7.86 & 2.12 \\
\cline { 2 - 4 } & $C_{5}$ & 5.12 & 5.32 \\
\hline
\end{tabular}

\subsubsection{Irregularities in the building plan}

With respect to irregularities in the building plan, three alternatives, namely asymmetrical with depression and protrusion $\left(K_{1}\right)$, symmetrical with depression and protrusion $\left(K_{2}\right)$ and symmetrical with no depression or protrusion $\left(K_{3}\right)$ were compared. Table 19 shows averages of experts' scores for irregularity in the building plan. All in all, $K_{3}$ with scores of 8.94, 8.91, 8.76, 8.94 and 7.12 is
Table 19. Averages of experts' scores for alternatives of the irregularities in the building plan within the major index

\begin{tabular}{|c|c|c|c|c|}
\hline \multirow{2}{*}{\multicolumn{2}{|c|}{ Irregularity in the building plan }} & \multicolumn{3}{|c|}{ Alternatives } \\
\hline & & \multirow{2}{*}{$\begin{array}{c}K_{1} \\
2.87 \\
\end{array}$} & \multirow{2}{*}{$\begin{array}{c}K_{2} \\
4.88 \\
\end{array}$} & \multirow{2}{*}{$\begin{array}{c}K_{3} \\
8.94 \\
\end{array}$} \\
\hline \multirow{5}{*}{ index } & $C_{1}$ & & & \\
\hline & $C_{2}$ & 2.19 & 5.22 & 8.91 \\
\hline & $C_{3}$ & 1.21 & 5.32 & 8.76 \\
\hline & $C_{4}$ & 1.12 & 5.32 & 8.94 \\
\hline & $C_{5}$ & 2.33 & 5.24 & 7.12 \\
\hline
\end{tabular}

determined to be the best alternative, and $K_{1}$ is decided the worst one.

\subsubsection{Irregularities in the facade}

Table 20 displays averages of experts' scores for irregularities in the façade. Four alternatives of the façade, i.e., with depression in the height of the building $\left(L_{1}\right)$, façade with protrusion of more than $25 \%$ of the length of the building $\left(L_{2}\right)$, façade with protrusion of less than $25 \%$ of the building length $\left(L_{3}\right)$ and façade with no depression and protrusion $\left(L_{4}\right)$ were assessed. In all indexes - except $C_{5}-L_{4}$ is the best alternative with scores of 7.94, 8.19, 8.89 and 8.87. In index $C_{1}$, two alternatives: $L_{1}$ and $L_{4}$ with nearly equal scores are the best. In index $C_{5}, L_{2}$ is defined as the best alternative with the rating of 8.96.

Table 20. Averages of experts' scores for alternatives of the irregularities in the facade in the major indexes

\begin{tabular}{|c|c|c|c|c|c|}
\hline \multirow{2}{*}{\multicolumn{2}{|c|}{ Irregularity in façade }} & \multicolumn{4}{|c|}{ Alternatives } \\
\hline & & \multirow{2}{*}{$\begin{array}{c}L_{1} \\
7.92 \\
\end{array}$} & \multirow{2}{*}{$\begin{array}{c}L_{2} \\
1.95 \\
\end{array}$} & \multirow{2}{*}{$\begin{array}{c}L_{3} \\
4.31 \\
\end{array}$} & \multirow{2}{*}{$\begin{array}{c}L_{4} \\
7.94 \\
\end{array}$} \\
\hline \multirow{5}{*}{ index } & $C_{1}$ & & & & \\
\hline & $C_{2}$ & 5.1 & 2.2 & 4.1 & 8.19 \\
\hline & $C_{3}$ & 4.07 & 1.11 & 2.21 & 8.89 \\
\hline & $C_{4}$ & 3.98 & 1.05 & 1.22 & 8.87 \\
\hline & $C_{5}$ & 3.04 & 8.96 & 7.01 & 5.23 \\
\hline
\end{tabular}

\subsubsection{Placement of the building form with respect to ground surface}

Table 21 shows averages of experts' scores concerning placement of the building form with respect to ground surface. Four alternatives, i.e., of higher than ground surface $\left(M_{1}\right)$, on the ground $\left(M_{2}\right)$, half-buried $\left(M_{3}\right)$ and buried $\left(M_{4}\right)$ were evaluated. Alternative $M_{4}$ with the rating of 8.94 in index $C_{1}$ is the best while as to indexes $C_{2}, C_{3}$ and $C_{4}$, with scores of 8.22, 8.78 and 8.76, respectively it is $M_{2}$ which is the best alternative. As to index $C_{5}$, nearly all alternatives have been scored the same.

\subsection{The rapid assessment model of vulnerability of office buildings form to blast}

Finally, to compute the final rating of the vulnerability of office buildings to explosion, the following stages must be performed with regard to alternatives in hand. The 
Table 21. Averages of experts' scores for alternatives of placement of the building form towards ground surface within the major indexes

\begin{tabular}{c|c|c|c|c|c}
\hline \multirow{2}{*}{$\begin{array}{l}\text { Placement of the building form } \\
\text { with respect to ground surface }\end{array}$} & \multicolumn{4}{|c}{ Alternatives } \\
\cline { 2 - 6 } & $M_{1}$ & $M_{2}$ & $M_{3}$ & $M_{4}$ \\
\hline \multirow{4}{*}{ index } & $C_{1}$ & 1.08 & 2.78 & 6.98 & 8.94 \\
\cline { 2 - 6 } & $C_{2}$ & 4.33 & 8.22 & 6.4 & 5.32 \\
\cline { 2 - 6 } & $C_{3}$ & 6.07 & 8.78 & 4.24 & 1.09 \\
\cline { 2 - 6 } & $C_{4}$ & 5.67 & 8.76 & 4.21 & 1.18 \\
\cline { 2 - 6 } & $C_{5}$ & 5.29 & 5.23 & 5.39 & 5.42 \\
\hline
\end{tabular}

proposed model was conducted on Swiss Re Tower as the case sample. The reason of the selection is that Swiss Re is one of the most famous office buildings in the world and has a special form. The paper intends to evaluate vulnerabilities of Swiss Re Tower in order to consider measures for mitigation of its vulnerabilities in the future.
This office building has 41 floors and, as the first ecological tower in London, was technically, architecturally, socially and spatially designed with a novel approach, The shape resembles a cylinder the profile of which becomes gradually thicker towards the middle until it obtains maximum thickness, it reaches minimum thickness towards the top. This form is compatible to favourable conditions because it is small and its site is limited; it has other benefits as well; e.g. on account of curvature of the surface, its volume limits the views of adjacent buildings in a smaller degree than cubic buildings. In addition, the curvature of the surface causes reduction in reflection of the sunlight to in adjacent buildings and leads to maximum amount of sunlight penetrating into the building. The remarkable point, making it prominent architecturally, is compatibility with the environment. Natural factors such as sunlight and wind can be enjoyed, ensuring comfort for the users. The building is better adapted to the environment because energy consumption is reduced. Thanks to natural ventilation system and double-shelled

Table 22. Calculation table of scores of indexes $\left(U_{i}\right)$

\begin{tabular}{|c|c|c|c|c|c|c|c|c|c|c|c|c|c|c|}
\hline$u_{1, j} \times w_{1, j}$ & $w_{3, j}$ & & $u_{3, j}$ & & $u_{2, j} \times w_{2, j}$ & $w_{2, j}$ & & $u_{2, j}$ & & $u_{1, j} \times w_{1, j}$ & $w_{1, j}$ & & $u_{1, j}$ & \\
\hline 1.47 & 0.166 & $w_{3,1}$ & 5.27 & $u_{3,1}$ & 0.36 & 0.173 & $w_{2,1}$ & 5.96 & $u_{2,1}$ & 0.14 & 0.105 & $w_{1,1}$ & 1.32 & $u_{1,1}$ \\
\hline 0.70 & 0.079 & $w_{3,2}$ & 4.1 & $u_{3,2}$ & 0.24 & 0.144 & $w_{2,2}$ & 3.22 & $u_{2,2}$ & 0.28 & 0.088 & $w_{1,2}$ & 3.18 & $u_{1,2}$ \\
\hline 0.19 & 0.022 & $w_{3,3}$ & 3.22 & $u_{3,3}$ & 0.09 & 0.023 & $w_{2,3}$ & 8.97 & $u_{2,3}$ & 0.59 & 0.064 & $w_{1,3}$ & 9.23 & $u_{1,3}$ \\
\hline 0.31 & 0.035 & $w_{3,4}$ & 1.22 & $u_{3,4}$ & 0.32 & 0.036 & $w_{2,4}$ & 1.9 & $u_{2,4}$ & 0.46 & 0.074 & $w_{1,4}$ & 6.16 & $u_{1,4}$ \\
\hline 0.85 & 0.105 & $w_{3,5}$ & 8.11 & $u_{3,5}$ & 0.41 & 0.046 & $w_{2,5}$ & 8.95 & $u_{2,5}$ & 0.66 & 0.075 & $w_{1,5}$ & 8.79 & $u_{1,5}$ \\
\hline 0.14 & 0.027 & $w_{3,6}$ & 5.19 & $u_{3,6}$ & 0.24 & 0.027 & $w_{2,6}$ & 3.24 & $u_{2,6}$ & 0.21 & 0.067 & $w_{1,6}$ & 3.12 & $u_{1,6}$ \\
\hline 0.20 & 0.063 & $w_{3,7}$ & 3.12 & $u_{3,7}$ & 0.14 & 0.028 & $w_{2,7}$ & 5.17 & $u_{2,7}$ & 0.51 & 0.071 & $w_{1,7}$ & 7.17 & $u_{1,7}$ \\
\hline 0.69 & 0.079 & $w_{3,8}$ & 2.29 & $u_{3,8}$ & 0.57 & 0.111 & $w_{2,8}$ & 4.2 & $u_{2,8}$ & 0.72 & 0.087 & $w_{1,8}$ & 8.23 & $u_{1,8}$ \\
\hline 0.23 & 0.103 & $w_{3,9}$ & 8.09 & $u_{3,9}$ & 0.19 & 0.086 & $w_{2,9}$ & 8.98 & $u_{2,9}$ & 0.24 & 0.081 & $w_{1,9}$ & 3.02 & $u_{1,9}$ \\
\hline 0.74 & 0.138 & $w_{3,10}$ & 5.32 & $u_{3,10}$ & 0.46 & 0.089 & $w_{2,10}$ & 5.22 & $u_{2,10}$ & 0.41 & 0.085 & $w_{1,10}$ & 4.88 & $u_{1,10}$ \\
\hline 0.56 & 0.137 & $w_{3,11}$ & 8.89 & $u_{3,11}$ & 0.32 & 0.064 & $w_{2,11}$ & 8.19 & $u_{2,11}$ & 0.61 & 0.077 & $w_{1,11}$ & 7.94 & $u_{1,11}$ \\
\hline 0.41 & 0.047 & $w_{3,12}$ & 8.78 & $u_{3,12}$ & 1.43 & 0.174 & $w_{2,12}$ & 8.22 & $u_{2,12}$ & 0.35 & 0.126 & $w_{1,12}$ & 2.78 & $u_{1,12}$ \\
\hline 5.88 & \multicolumn{4}{|c|}{$U_{3}$} & 6.07 & \multicolumn{4}{|c|}{$U_{2}$} & 5.18 & \multicolumn{4}{|c|}{$U_{1}$} \\
\hline
\end{tabular}

\begin{tabular}{|c|c|c|c|c|c|c|c|c|c|}
\hline$u_{5, j} \times w_{5, j}$ & $w_{5, j}$ & & $u_{5, j}$ & & $u_{4, j} \times w_{4, j}$ & $w_{4, j}$ & & $u_{4, j}$ & \\
\hline 1.68 & 0.188 & $w_{5,1}$ & 5.22 & $u_{5,1}$ & 1.73 & 0.195 & $w_{4,1}$ & 5.19 & $u_{4,1}$ \\
\hline 0.60 & 0.069 & $w_{5,2}$ & 5.9 & $u_{5,2}$ & 0.57 & 0.064 & $w_{4,2}$ & 4.13 & $u_{4,2}$ \\
\hline 0.40 & 0.051 & $w_{5,3}$ & 3.34 & $u_{5,3}$ & 0.29 & 0.033 & $w_{4,3}$ & 3.16 & $u_{4,3}$ \\
\hline 0.09 & 0.036 & $w_{5,4}$ & 7.91 & $u_{5,4}$ & 0.42 & 0.047 & $w_{4,4}$ & 1.23 & $u_{4,4}$ \\
\hline 0.64 & 0.120 & $w_{5,5}$ & 5.34 & $u_{5,5}$ & 0.78 & 0.100 & $w_{4,5}$ & 7.77 & $u_{4,5}$ \\
\hline 0.17 & 0.032 & $w_{5,6}$ & 3.23 & $u_{5,6}$ & 0.18 & 0.034 & $w_{4,6}$ & 5.12 & $u_{4,6}$ \\
\hline 0.67 & 0.091 & $w_{5,7}$ & 7.34 & $u_{5,7}$ & 0.19 & 0.057 & $w_{4,7}$ & 3.33 & $u_{4,7}$ \\
\hline 0.74 & 0.118 & $w_{5,8}$ & 7.38 & $u_{5,8}$ & 0.56 & 0.063 & $w_{4,8}$ & 2.22 & $u_{4,8}$ \\
\hline 0.14 & 0.027 & $w_{5,9}$ & 5.12 & $u_{5,9}$ & 0.16 & 0.074 & $w_{4,9}$ & 7.86 & $u_{4,9}$ \\
\hline 0.82 & 0.156 & $w_{5,10}$ & 5.24 & $u_{5,10}$ & 0.80 & 0.150 & $w_{4,10}$ & 5.32 & $u_{4,10}$ \\
\hline 0.23 & 0.076 & $w_{5,11}$ & 5.23 & $u_{5,11}$ & 0.50 & 0.125 & $w_{4,11}$ & 8.87 & $u_{4,11}$ \\
\hline 0.19 & 0.036 & $w_{5,12}$ & 5.23 & $u_{5,12}$ & 0.50 & 0.057 & $w_{4,12}$ & 8.76 & $u_{4,12}$ \\
\hline 5.67 & \multicolumn{4}{|c|}{$U_{5}$} & 5.71 & \multicolumn{4}{|c|}{$U_{4}$} \\
\hline
\end{tabular}


façade of the tower, the forced ventilation system is off for $40 \%$ of the year, and the use of natural light decreases dependence on the electrical lighting system. The cross section of the building reduces wind deviation downwards compared to a rectangular tower with equal dimensions. Double-glazed façade is cooled by the air coming from the offices and, therefore, overall temperature of the building remains very low. Moreover, the air is stored between two glazed layers and insulates the internal office space. The positive architectural, environmental and energy features of the building were evaluated in the article it in terms of vulnerability to explosion.

This building consists of an overall cylindrical form, a combination of a radial form, a corner articulation and a convex shell. On the other hand, its architectural form completely conforms to the structural form, and there is conformity between the architectural form and the environment. Furthermore, there is coherence between architecture elements of the building and proportion of the width to the height assessed at is less than one. The plan of this building is symmetrical if judging depression and protrusion; the façade has no depression or protrusion and the same is true about its setting on the ground (see Fig. 2).

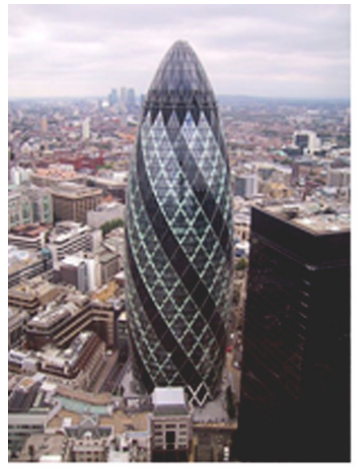

(A)

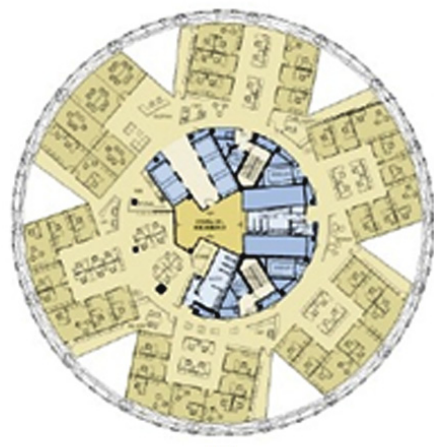

(B)
Fig. 2. (A) Exterior façade of Swiss Re Tower; (B) The plan of Swiss Re Tower (Foster 2015)

Rating of Swiss Re Tower has been calculated as follows.

Step 1) Achieving score of each of the alternatives based on Tables 10 to 21 . For example: $u_{1,1}$ means the score of the cylinder form alternative at $1^{\text {st }}$ sub-index and $1^{\text {st }}$ index $\left(C_{1}\right)$ that is equivalent to 1.32 as shown in Table 10. Step 2) The weight of each sub-index at each major index is procured based on Tables 5 to 9. For example, $w_{11}$ means the weight of the sub-index $C_{1-1}$ which equals 0.105 as shown in Table 5. Step 3) $U_{i}$ is calculated using Eqn (1). Scores of each of major index are obtained via adding numbers in the columns $u_{i, j} \times w_{i, j}$. For example, the sum of numbers of column $u_{1, j} \times w_{1, j}$ is equivalent to $U_{1}$ (Table 22).

Step 4) $U$ is calculated using Eqn (2). In this stage, the total score is obtained through adding numbers in the columns $W_{j} \times U_{j}$. This rating is equivalent to 5.59 for the case study, as shown in Table 23.
Table 23. Calculation table of overall score (U)

\begin{tabular}{c|c|c|c}
\hline$W_{j} \times U_{j}$ & $U_{j}$ & $W_{j}$ & $C_{j}$ \\
\hline 2.02 & 5.18 & 0.390 & $C 1$ \\
\hline 1.32 & 6.07 & 0.217 & $C 2$ \\
\hline 0.59 & 5.88 & 0.100 & $C 3$ \\
\hline 0.93 & 5.71 & 0.163 & $C 4$ \\
\hline 0.74 & 5.67 & 0.130 & $C 5$ \\
\hline 5.59 & \multicolumn{3}{|c}{$U$} \\
\hline
\end{tabular}

Step 5) Final score $(L)$ of the building is obtained according to Eqn (3):

$$
L=(U / 9) \times 100=(5.59 / 9) \times 100=62.11 \% .
$$

Thus, final score of the office building is $62.11 \%$. According to Table 2, this building is evaluated as standing at the medium level, and the architectural form of this office building has medium vulnerability to blast.

\section{Conclusions}

In order to present a model for rapid assessment of vulnerability of architectural form of office buildings tot explosion, major index - including the ability to reduce blast effect, relationship among spaces in the crisis condition, simplicity of implementation, economic factors and creating the least least unusable space - were considered. According to experts' views, they cover all significant aspects necessary to evaluate vulnerability of architectural form of office buildings to blast. In this model, according to the experts, index of capability to reduce blast effects takes the first place with the weight of $39.03 \%$. The index of relationship among spaces in the crisis condition, with the weight of, $21.68 \%$ is ranked as second. The economic index, the index of creating the least unusable space and simplicity of implementation have, respectively, the weights of $16.26 \%, 13.01 \%$ and $10.01 \%$. Moreover, represented in this model, are sub-indexes including: general form of the building, combination of building forms, articulation of corners of forms, variety of roofs, conformity of the architectural form with the structural form, conformity of the architectural form with the environment, coherence or connection between architectural elements with each other, the shape of the surface of exterior shell, ratio of width to height of the building, irregularities in the building plan, irregularities in the façade and placement of building form on the ground. All the sub-indexes were applied, as they cover all important aspects of architecture form of office buildings, according to the experts' opinions. In each major index, in experts' views and according to SWARA procedure, sub-indexes were weighted and prioritized as follows:

1) Regarding the major index of capability to decrease blast effect, remembering that location underground or over ground is crucial in case of blast, the subindex of placement of the building on the ground 
surface results in the weight of $12.62 \%$. The overall form of the building and combination of building forms place those sub-indexes in the second and third place, respectively, with weights of $10.52 \%$ and $8.76 \%$.

2) Regarding the major index of relationship among spaces in the crisis condition, sub-indexes including placement of the building form on the ground surface, overall form of the building, and combination of building forms place those sub-indexes in the first to third place, respectively, with the weights of $17.44 \%, 17.27 \%$ and $14.39 \%$.

3) Regarding the major index of simplicity of implementation, sub-indexes including placement of the building form on the ground surface, irregularity in the building plan and irregularity in the façade place those sub-indexes in the first to third place, respectively, with the weights of $16.58 \%, 13.82$ and $13.68 \%$.

4) Regarding the major index reflecting economic factors, sub-indexes including general form of the building, irregularity in the building plan and irregularity in the façade were ranked in order of first to third with weights of $19.50 \%, 15.00 \%$ and $12.50 \%$.

5) Regarding the major index of the least unusable space, sub-indexes including placement of the building form on the ground surface, irregularity in the building plan and conformity of the architecture form with the structural form gained first to third places, respectively with weights of $18.77 \%, 15.64 \%$ and $12.03 \%$.

The model for evaluating vulnerability of architecture form of office buildings to blast, presented in the paper uses figures between zero and a hundred; the closer the figure to a hundred, the less vulnerable an architectural form of office building is to blast. Furthermore, four levels were defined for the final rating of the building including weak, medium, good and excellent, therefore the final assessment may be both qualitative and quantitative. Another advantage of this model is that it determines vulnerable or weak spots of the architecture form of an office building in case of an explosion. Working towards removing these points, and keeping in mind the final rating of the building, it is possible to create a building less vulnerable to explosion. Studying on Swiss Re Tower as a case resulted in a rating of $62.11 \%$ for vulnerability of this building to blast which means that, in assessment, it may be placed at the medium level.

\section{References}

Ahmadi, M. A.; Ebadi, M. 2014. Evolving smart approach for determination dew point pressure through condensate gas reservoirs, Fuel 117(B): 1074-1084.

Asgharian Jedi, A. 2007. Architectural obligations in sustainable civil defense. Shahid Beheshti University, Tehran.

Asgharpour, M. J. 1998. Multicriteria decision making. Tehran: Tehran University Press.
Barakat, M.; Hetherington, J. G. 1998. New architectural forms to reduce the effects of blast waves and fragments on structures, Structures under Shock and Impact 5: 53-62.

Bitarafan, M. 2012. Survey architectural styles and codification indicators of compatible architecture with the principles of civil defense: MSc thesis. Maleke-Ashtar University of Technology, Department of Civil Defense, Tehran.

Bitarafan, M.; Zolfani, S. H.; Arefi, S. L.; Zavadskas, E. K. 2012. Evaluating the construction methods of cold-formed steel structures in reconstructing the areas damaged in natural crises, using the methods AHP and COPRAS-G, Archives of Civil and Mechanical Engineering 12(3): 360367. http://dx.doi.org/10.1016/j.acme.2012.06.015

Bitarafan, M.; Hosseini, B.; Hashemi-Fesharaki, J.; Esmailzadehd, A. 2013. Role of architectural space in blast-resistant buildings, Frontiers of Architectural Research 2(1): 67-73. http://dx.doi.org/10.1016/j.foar.2012.11.003

Bitarafan, M.; Zolfani, S. H.; Arefi, S. L.; Zavadskas, E. K.; Mahmoudzadeh, A. 2014. Evaluation of real-time intelligent sensors for structural health monitoring of bridges based on SWARA-WASPAS; a case in Iran, Baltic Journal of Road and Bridge Engineering 9(4): 333-340. http://dx.doi.org/10.3846/bjrbe.2014.40

Chou, S. Y.; Chang, Y. H. 2008. A decision support system for supplier selection based on a strategy - aligned fuzzy SMART approach, Expert Systems with Applications 34(4): 2241-2253. http://dx.doi.org/10.1016/j.eswa.2007.03.001

Coolset, R. 2010. EU counterterrorism strategy: value added or chimera, International Affairs 86(4): 857-873. http://dx.doi.org/10.1111/j.1468-2346.2010.00916.x

Dehnavi, A.; Aghdam, I. N.; Pradhan, B.; Varzandeh, M. H. M. 2015. A new hybrid model using step-wise weight assessment ratio analysis (SWAM) technique and adaptive neuro-fuzzy inference system (ANFIS) for regional landslide hazard assessment in Iran, Catena 135: 122-148. http://dx.doi.org/10.1016/j.catena.2015.07.020

Federal Emergency Management Agency (FEMA). 2003. Reference manual to mitigate terrorist attacks against buildings. FEMA-426. Risk Management Series.

Federal Emergency Management Agency (FEMA). 2007. Site and urban design for security. FEMA-430, Risk Management Series.

Foster, N. 2015. Figure 2 [online], cited [1 December 2015]. Available from Internet: http://5osa.com/entry/NormanFoster-Swiss-Re-London-Headquarters

Gebbeken, N.; Döge, T. 2010. Explosion protection-architectural design, urban planning and landscape planning, International Journal of Protective Structures 1(1): 1-22. http://dx.doi.org/10.1260/2041-4196.1.1.1

Ginevicius, R. 2011. A new determining method for the criteria weights in multicriteria evaluation, International Journal of Information Technology \& Decision Making 10(6): 10671095. http://dx.doi.org/10.1142/S0219622011004713

Graham, S. 2006. Cities and the war on terror, International Journal of Urban and Regional Research 30(2): 255-276. http://dx.doi.org/10.1111/j.1468-2427.2006.00665.x

Hashemkhani Zolfani, S.; Bahrami, M. 2014. Investment prioritizing in high tech industries based on SWARA-COPRAS approach, Technological and Economic Development of Economy 20(3): 534-553. http://dx.doi.org/10.3846/20294913.2014.881435

Jasiński, A. 2010. Technical and technological measures of securing buildings against terrorist attack, Technical Transactions, Architecture 8-A 107(18): 81-91.

Kaplinski, O.; Peldschus, F.; Tupenaite, L. 2014. Development of MCDM methods - in Honour of professor Edmundas Kazimieras Zavadskas on the occasion of his $70^{\text {th }}$ birth- 
day, International Journal of Computers Communications \& Control 9(3): 305-312.

http://dx.doi.org/10.15837/ijccc.2014.3.1084

Kaplinski, O.; Tamošaitienė, J. 2015. Analysis of normalization methods influencing results: a review to Honour Professor Friedel Peldschus on the occasion of his $75^{\text {th }}$ Birthday, Procedia Engineering 122: 2-10.

http://dx.doi.org/10.1016/j.proeng.2015.10.001

Keršulienè, V.; Turskis, Z. 2014. An integrated multi-criteria group decision making process: selection of the chief accountant, Procedia - Social and Behavioral Sciences 110: 897-904. http://dx.doi.org/10.1016/j.sbspro.2013.12.935

Kersuliene, V.; Zavadskas, E. K.; Turskis, Z. 2010. Selection of rational dispute resolution method by applying New Step-Wise Weight Assessment Ratio Analysis (SWARA), Journal of Business Economics and Management 11(2): 243-258. http://dx.doi.org/10.3846/jbem.2010.12

Lazauskaite, D.; Burinskiene, M.; Podvezko, V. 2015. Subjectively and objectively integrated assessment of the quality indices of the suburban residential environment, International Journal of Strategic Property Management 19(3): 297-308. http://dx.doi.org/10.3846/1648715X.2015.1051164

Łodygowski, T.; Garstecki, A. (Eds). 2012. Security of buildings in conditions of the terrorist threat. Poznań: Poznań University of Technology Press (in Polish).

Lootsma, F. A. 1996. A model for the relative importance of the criteria in the multiplicative AHP and SMART, European Journal of Operational Research 94: 467-476. http://dx.doi.org/10.1016/0377-2217(95)00129-8

Ruzgys, A.; Volvaciovas, R.; Ignatavicius, C.; Turskis, Z. 2014. Integrated evaluation of external wall Insulation in residential buildings using SWARA-TODIM MCDM method, Journal of Civil Engineering and Management 20(1): 103-110. http://dx.doi.org/10.3846/13923730.2013.843585
Saaty, L. T. 1980. The analytic hierarchy process. New York: McGraw Hill Company.

Saaty, L. T.; Vargas, G. L. 2007. Dispersion of group judgments, Mathematical and Computer Modelling 46(7-8): 918-925. http://dx.doi.org/10.1016/j.mcm.2007.03.004

Shannon, C. E. 1948. A mathematical theory of communication, Bell System Technical Journal 27(3): 379-423. http://dx.doi.org/10.1002/j.1538-7305.1948.tb01338.x

Stanujkic, D.; Karabasevic, D.; Zavadskas, E. K. 2015. A framework for the selection of a packaging design based on the SWARA method, Inzinerine Ekonomika-Engineering Economics 26(2): 181-187. http://dx.doi.org/10.5755/j01.ee.26.2.8820

Vafaeipour, M.; Hashemkhani Zolfani, S.; Varzandeh, M. H. M.; Derakhti, A.; Keshavarz Eshkalag, M. 2014. Assessment of regions priority for implementation of solar projects in Iran: New application of a hybrid multi-criteria decision making approach, Energy Conversion and Management 86: 653-663. http://dx.doi.org/10.1016/j.enconman.2014.05.083

Van den Honert, R. C. 2001. Decisional power in group decision making: a note on the allocation of group members' weights in the multiplicative AHP and SMART, Group Decision and Negotiation 10(3): 275-286. http://dx.doi.org/10.1023/A:1011201501379

Zavadskas, E. K.; Antuchevičienè, J.; Kaplinski, O. 2015a. Multi-criteria decision making in civil engineering, Part 1 A state-of-the-art survey, Engineering Structures and Technologies 7(3): 103-113. http://dx.doi.org/10.3846/2029882X.2015.1143204

Zavadskas, E. K.; Antuchevičienè, J.; Kaplinski, O. 2015b. Multi-criteria decision making in civil engineering, Part 2 - Applications, Engineering Structures and Technologies 7(4): 151-167. http://dx.doi.org/10.3846/2029882X.2016.1139664

Jalal NAKHAEI. He is currently PhD in Art and Architecture Engineering in Science and Research Branch Islamic Azad University, Tehran, Iran. His research areas are architectural engineering, secure space and structures, explosion protection.

Mahdi BITARAFAN. PhD Student of Earthquake Engineering in Engineering Research Institution of Natural Disaster Shakhes Pajouh, Isfahan, Iran. Research interests: earthquake engineering, civil engineering, retrofitting and strengthening on steel and concrete structures, explosion protection, multiple criteria decision making.

Shahin LALE AREFI. PhD Candidate of Structural Engineering at the University of Mohaghegh Ardabili, Ardabil, Iran. Research interests: civil engineering, earthquake engineering, experimental, composite materials, retrofitting and strengthening on steel and concrete structures, modeling and analytical research on steel and composite structural, multiple criteria decision making, damage detection, optimal sensor placement.

Oleg KAPLIŃSKI. He is Professor of CE at Faculty of Architecture (IAP), Poznan University of Technology, Poznań, Poland. He lectures in economics and organization of the investment process, as well as theory and principles of work places design. The author of 240 publications. Doctor Honoris Causa of VGTU (1996). Member of the CE Committee of the Polish Academy of Sciences. His current research focuses on: integral management, integral design, risk management, theory of decision making and research methods in $\mathrm{CE}$ and architecture. 